Fanum

Sociológico
Forum Sociológico

Série II

21 | 2011

Transformação urbana

\title{
Reinventar a relação cidade-montanha na Covilhã: uma discussão para a criação de uma nova marca urbana
}

Domingos Vaz

\section{(2) OpenEdition \\ Journals}

Edição electrónica

URL: https://journals.openedition.org/sociologico/444

DOI: $10.4000 /$ sociologico. 444

ISSN: 2182-7427

Editora

CICS.NOVA - Centro Interdisciplinar de Ciências Sociais da Universidade Nova de Lisboa

Edição impressa

Data de publição: 1 dezembro 2011

Paginação: 55-64

ISSN: 0872-8380

Refêrencia eletrónica

Domingos Vaz, «Reinventar a relação cidade-montanha na Covilhã: uma discussão para a criação de uma nova marca urbana», Forum Sociológico [Online], 21 | 2011, posto online no dia 05 setembro 2012, consultado o 30 março 2022. URL: http://journals.openedition.org/sociologico/444 ; DOI: https:// doi.org/10.4000/sociologico.444

Este documento foi criado de forma automática no dia 30 março 2022

(c) CICS.NOVA 


\title{
Reinventar a relação cidade- montanha na Covilhã: uma discussão para a criação de uma nova marca urbana
}

\author{
Domingos Vaz
}

\section{O problema}

1 As cidades portuguesas, em particular as de dimensão intermédia, registaram profundas alterações no período que se sucedeu à instauração do regime democrático em 1974. A partir de então, o reforço do poder autárquico aliado a novas práticas de planeamento deu origem a diversos processos de investimento público e privado, de cariz infra-estrutural e imobiliário, que alargaram as manchas urbanas muito para lá dos seus centros tradicionais.

2 Sem constituir um lugar excepcional no quadro desta temática, a Covilhã representa mesmo assim uma original situação, rara no urbanismo português, de "cidade de montanha", com a expressão de uma larga tradição industrial, firmada nas épocas moderna e contemporânea. Considera-se, portanto, a necessidade de reflectir o sentido do conjunto da sua estruturação urbana, de forma a permitir uma visão global para o reordenamento desta urbe multissecular.

3 Numa povoação encastrada nas faldas de uma montanha foi-se estruturando uma cidade de meia encosta como um "enclave da industrialização". o geógrafo Orlando Ribeiro, a propósito da condição serrana desta cidade, explicaria que ela "ocupa um espaço constrangido, pesada herança das imposições do seu sítio genético", formado no tempo em que a lã e a torrente das ribeiras eram as determinantes de que vivia (1994: 260). A presença fabril e a sua interposição com a malha urbana levará a uma configuração de "cidade-fábrica", um perfil geo-histórico que se vai manter praticamente inabalado até à década de 1980 com o declínio dos lanifícios ${ }^{1}$. 
4 A montanha é atributo fundacional, e ainda hoje a apreensão da cidade, na plenitude das suas dinâmicas e representações, não dispensa o aprofundamento do significado local, material e cultural de três referentes principais que pesquisamos no âmbito de um estudo sobre as representações urbanas locais. Destacamos o primeiro deles - a serra da Estrela -, que tem um valor ambiental e paisagístico e, por isso, centralidade na problemática objecto deste texto. O segundo é a Universidade, associada à reestruturação da cidade na época contemporânea, e o terceiro moldou a feição sóciohistórica da urbe tradicional que subsiste no imaginário local, a indústria de lanifícios (Vaz, 2004b). É, assim, evidenciada a aproximação à montanha enquanto matéria simbólica que perdura de forma marcante no imaginário local, adquirindo interesse reflectir e interpelar as razões que levaram a que um tal "capital" simbólico não tenha sido objecto ou apenas tido uma débil apropriação nas opções locais de planeamento urbano. Admite-se que esta dimensão ontológica, a aproximação à montanha, detém potencial para influenciar a forma urbana, se devidamente trabalhada para singularizar a Covilhã no contexto mais vasto.

5 Ao invés, a pós-“cidade-fábrica” desceu para a zona de vale de forma desconexa com a cidade antiga, sem um desenho de conjunto coerente com a topografia natural, dando lugar a uma estruturação urbana desordenada com um efeito tão devastador na paisagem que o arquitecto Teotónio Pereira acredita não ter paralelo em nenhuma outra cidade portuguesa ${ }^{2}$, e que numa crítica directa à Covilhã actual a descreve como "desfigurada" no seu contorno urbano (skyline) e “(...) com extensões recentes desgarradas ocupando terrenos férteis e destruindo paisagens ancestrais (...)"3. Esta crítica é partilhada por outros arquitectos e urbanistas de dimensão nacional. Para José Manuel Fernandes (2009: 50): “A evolução desta área foi problemática: não se trata já de a edificação da «baixa» moderna da cidade falhar (...), mas sim de a sua consolidação urbana ter sido desqualificada, não tendo seguido um plano ordenador, e tendo-se possivelmente arrastado excessivamente no tempo". Por sua vez, Madalena Cunha Matos (2009: 115) escreve:

Esta cidade, que foi necessária à formação do país e ao aproveitamento das potencialidades do meio natural que a envolve - pastagens para os rebanhos e águas para o fabrico -, há pouco passou a um estado de improbabilidade, pelo dizimar da beleza que a tornaria atractiva para o turismo - a mole imensa da serra, servindo como pano de fundo, e de consolo a um aglomerado com demasiados trechos desordenados, feios e rebarbativos.

Perguntamo-nos quais as razões que levaram a que os valores ambientais e paisagísticos não tenham sido suficientemente defendidos.

7 Tendo presente que, na maioria dos casos, cada cidade tem os seus criadores literários e artísticos que lhe imprimiram um imaginário, naquilo que poderíamos designar como reconstrutores da sua memória colectiva (Neves, 2008), tem interesse apurar a maneira como na Covilhã os registos tanto literários como pictóricos relacionam a cidade com a montanha, sobretudo em termos paisagísticos, dada a sua topografia montanhosa. Com este contributo propomo-nos, primeiro, conhecer como essa condição montanhesca da urbe é representada em registos literários mas também pictóricos, e, em segundo lugar, discutir como ela é integrada ou está presente nas figuras de planeamento urbanístico, ou seja, saber em que sentido a condição matricial serrana influencia a própria produção ou desenho da forma urbana. 


\section{Representação literária e pictórica da cidade enquadrada na montanha}

8 Na sua colectânea Escritores do Concelho da Covilhã, José Mendes dos Santos (1997) identifica os autores de alguma forma ligados à cidade, encontrando-se aí algumas referências que a associam à montanha. As referências são na sua maioria de autores do século XX e enquadram-se frequentemente em publicações do período do Estado Novo, enaltecendo a "cidade neve".

9 O romance A Lã e a Neve de Ferreira de Castro (1947), que, não sendo da Covilhã, vai dar expressão ficcional à luta dos operários dos lanifícios num emblemático documento humano onde abundam as descrições topográficas da cidade, com os seus lugares ("Ao chegar às Portas do Sol, deteve-se, um instante, a ver as obras do mercado novo"), as suas praças e as suas ruas, enquadradas na serra: "Um dia, quando os operários da Covilhã e da Aldeia do Carvalho saíram de suas casas, viram todas as encostas, todas as dobras do terreno, todos os caminhos vestidos de branco. A cidade, num esporão da serra, parecia obra de fantasmagoria, com telhados e perfis inverosímeis" (1990: 150). O processo narrativo tem como centro o drama da gente no labor fabril dos lanifícios, que vivia e morria entre a lã e a neve.

10 Numa certa continuidade, e também como contributo para a reelaboração da memória da cidade através da literatura, referimos o romance Café Montalto, de Manuel da Silva Ramos (2003), um autor nascido na Covilhã, que elabora uma

"factoficção", como ele diz, numa aproximação ao real. Desta vez a memória incide sobre os acontecimentos que vão dos anos de 1960 até $1986^{4}$. Café Montalto é o lugar simbólico da estratificação social, o café dos industriais, onde não entravam os operários da Covilhã, por isso é ocupado (ficcionalmente) no primeiro de Maio de 1974. o livro é um acervo documental notável de figuras, de acontecimentos e de lugares urbanos serranos da Covilhã. 




11 No âmbito de um outro género literário, os guias de viagem, merece destaque, no primeiro quartel do século XX, o Guia de Portugal dirigido por Raul Proença, obra de referência reeditada pela Fundação Calouste Gulbenkian. Nele se salienta o carácter montanhesco da urbe e a sua ancestral actividade:

Alcandorada na ilharga da serra, a cavaleiro de um grandioso e oblíquo enrugamento, escavado de um lado pela ribeira da Carpinteira e do outro pela ribeira de Goldra, a cidade apresenta perspectivas singulares, consoante se descobre do vale, do alto ou dos flancos. (...) As ruas são traçadas com a bonomia e aspereza de carreiros de montanha. De todos os lados se ouve, ao percorrê-las, o matraquear dos teares e variada utensilagem das oficinas. A água, abundante, desce discretamente da serra, em tubagens, para as lavandarias, enquanto no fundo dos córregos se despenham livremente os caudais das duas ribeiras, sem dúvida as determinantes da fundação da secular indústria, se não da própria cidade. (1985: 725)

No Guia de Portugal verificamos que esta zona das Beiras era percorrida desde tempos remotos pelos rebanhos e pelos caminhos da transumância entre a montanha e as zonas baixas, o que explica a abundância da lã e das actividades laneiras e a fama das «baetas e surrobecos» do Teixoso, na proximidade da Covilhã (1985: 732).

13 Miguel Torga, na sua obra Portugal, traça um quadro poético das regiões do país, e descreve a Beira como dominada em todos os aspectos pela força telúrica da serra da Estrela (1980). Contudo, apenas menciona a Covilhã como berço de viajantes, nunca a associando directamente à paisagem serrana.

Apesar de não serem abundantes, existem obras literárias marcantes centradas na realidade social covilhanense com reflexos na inserção paisagística. Diz-nos M. João Matos (2010), que estudou a produção literária relacionada com os Alpes, que o facto de as descrições literárias sobre a paisagem montanhosa covilhanense serem escassas poderá explicar-se em parte pela situação excêntrica da serra da Estrela em relação à 
Europa, quando comparamos com a centralidade de outras cadeias montanhosas europeias, como sejam os Alpes, onde é abundante a literatura deixada por viajantes ilustres e redigida para turistas em busca de experiências estéticas. Uma realidade que não deve surpreender se lembrarmos que a serra da Estrela só em 1881 foi objecto da primeira expedição científica realizada pela Sociedade de Geografia de Lisboa, liderada pelo explorador Hermenegildo Capelo 5 . Uma idiossincrasia em termos de localização geográfica que parece ter prolongamento em termos culturais. Aires da Silva reforça esta tese, e dá conta das realizações, instituições e eventos de âmbito cultural com destaque na cidade, referindo áreas como o património, a arquitectura, a arte pública, a música, o teatro e a recreação, escrevendo:

A falta de monumentos e edifícios de notável valor arquitectónico deve-se à pobreza da terra, sujeita a crises da sua indústria, à interioridade, e, como se disse, à falta de Mecenas e de homens ricos voltados à cultura. O próprio granito da montanha é aqui impróprio para a cantaria e mais adequado à feitura de muralhas e castelos. E a degradação das muralhas começou, afinal, com uma ordem do próprio Rei D. José I. (1996: 129)

Da análise diacrónica e da observação da cidade actual, podemos deduzir, como escrevemos num outro momento, que "à importância económica da cidade não correspondeu um interesse arquitectónico ou artístico de especificidades notáveis" (Vaz, 2004b: 99-100). Esta é uma opinião partilhada por outros, incluindo Aires da Silva: "Salvo raras excepções, tem sido a Covilhã parca em mecenas, capazes de promover na sua terra a construção de grandes monumentos, ou sequer palácios de apreciável valor arquitectónico" (1996: 127).

16 A pintura, arte desde sempre ligada à paisagem de montanha e à identidade das mais belas cidades montanhescas, também é abordada por Aires da Silva. Contudo, os artistas que refere são recentes e não se dedicaram à representação pictórica da Covilhã inserida na paisagem montanhosa, mas antes a retratos ou a recantos pitorescos da cidade $^{6}$. Confirmando esta realidade, salienta-se que mesmo no Museu de Arte e Cultura da Covilhã nenhuma das obras de pintura expostas retrata a imagem da cidade em simbiose com a montanha. Apenas uma tapeçaria, já da segunda metade do século XX, representando diversos aspectos particulares da região, expressa essa ligação. Também nos frescos do Salão Nobre da Câmara Municipal, obra do pintor Lino António, encontramos imagens semelhantes: as gentes da serra, a pastorícia, a montanha, os desportos de Inverno. No entanto, a paisagem local, mesmo se não representada de forma directa, pode inspirar a criatividade, como o comprovam as palavras de um pintor nascido na Covilhã: "Para mim, pintar é algo de obsessivo, como que uma necessidade biológica. Sou um homem embevecido pelo espectáculo do mundo. Nasci na Covilhã e aí aprendi a olhar a paisagem. E não me canso de olhar as vastas perspectivas da minha infância." Esse olhar sobre a paisagem será com certeza uma das pistas a seguir na reconstrução de uma imagem renovada para esta cidade que valorize os seus belvederes.

\section{Aspectos da evolução urbana da Covilhã}

Da consulta de alguns estudiosos da historiografia local, verificamos que estes concordam num ponto: a Covilhã é uma povoação que cresceu de maneira invulgar (Pereira, 2009; Rodrigues, 2009). Na Idade Média, enquanto o arrabalde se desenvolvia a este e sudeste, o interior da cerca permanecia desabitado, facto que D. Fernando I 
tentou contrariar com a concessão de privilégios aos que ocupassem o interior da muralha, concessão esta logo depois revogada a pe-

dido dos moradores do arrabalde que concorria já, em importância e densidade, com a vila intra-muros ${ }^{8}$.

Figura 2 遥 Covilhã, áreas de incidência da antiga indústria dos lanifícios



Só no século XVI, com a confirmação dos privilégios aos moradores por D. Manuel, se densificou a ocupação do interior da cerca, "contrariando o sentido de crescimento urbano de outras vilas e cidades portuguesas que, geralmente, se expandiam de dentro para fora dos muros" (Pereira, 2009: 21-23). As construções desenvolveram-se ao longo de ruas e escadas estreitas adaptadas à topografia, ainda hoje bem presentes.

Desde cedo que o perfil económico da vila se associa aos recursos naturais da montanha. Já Gil Vicente falava, na Tragicomédia da Serra da Estrela (1527), "nos panos finos que se faziam lá". Pensa-se que a origem das actividades ligadas aos lanifícios se encontrará na população judaica, muito numerosa na região durante a Idade Média. Como principal núcleo de lanifícios de Portugal, a Covilhã desenvolve-se, graças, por um lado, às ribeiras afluentes do rio Zêzere - Carpinteira e da Goldra -, vindas da serra, que forneciam água para o tratamento das lãs e a força motriz e, por outro, na continuidade de uma tradição na actividade pastoril. Em 1681, D. Pedro II, conde da Ericeira, funda a Fábrica-Escola na ribeira da Carpinteira, antiga Fábrica d'el Rei D. Sebastião, mais tarde denominada «Fábrica Velha». Com a reforma do Marquês de Pombal, no século XVIII, funda-se a Real Fábrica de Panos da Covilhã junto à ribeira da Goldra $^{10}$, com as pedras provenientes da demolição da muralha medieval ${ }^{11}$. Em 1683 são instalados na Covilhã os primeiros teares Jeacquard; em 1884 é fundada a Escola Industrial Campos Melo e em 1891 inaugura-se a chegada do caminho-de-ferro, que impulsiona a indústria de lanifícios e a procura turística para os tratamentos de 
tuberculose e para os desportos de montanha (Silva, 1996; Pinheiro, 1997, 2009; Domingues, 2006; Rodrigues, 2009).

Herdados ou não da comunidade judaica, os lanifícios foram a actividade dominante na economia local e "industrializaram" a paisagem. Os seus efeitos na evolução urbana, quer do arrabalde quer da vila intra-muros, estão associados a muitas reedificações e as consequências urbanísticas serão muito significativas do ponto de vista dos desígnios futuros da Covilhã, imprimindo-lhe um carácter original sem paralelo em nenhuma outra cidade portuguesa, deixando fortes marcas identitárias até aos anos 70 do século XX (Ribeiro, 1994; Pinheiro, 2009).

Figura 3 通 Covilhã, UBI, pólo I, antiga Real Fábrica dos Panos

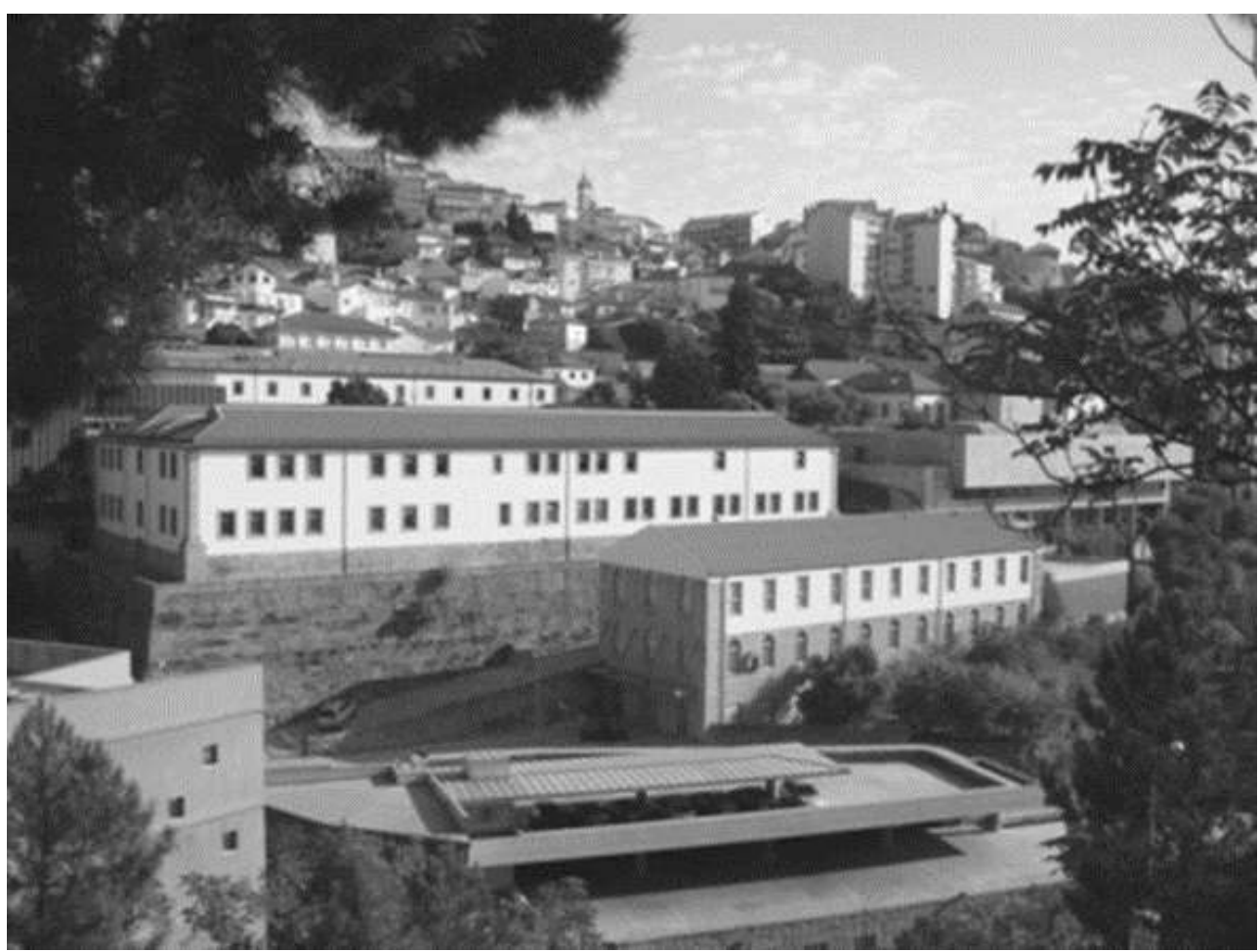

Os anos 40 do século XX, em pleno Estado Novo, marcam o início de um momento importante na transformação urbana da Covilhã. $O$ arquitecto João António de Aguiar é designado para elaborar o Anteplano Geral de Urbanização da Covilhã e o Plano Parcial de Urbanização da Área Compreendida entre o Largo do Pelourinho e a Estação de Caminho de Ferro, bem como para projectar a nova Praça do Município. Amplia-se a escala da cidade com introdução de uma nova rede de vias estruturantes, unindo a zona alta à baixa da cidade, acompanhada de novos equipamentos e bairros residenciais ${ }^{12}$.

Assiste-se nesta fase do Estado Novo a uma decisiva opção pela implantação dos chamados "bairros sociais" em núcleos isolados excêntricos relativamente ao núcleo urbano central. Um facto que, no contexto topográfico da cidade de montanha, agravou o sentido de gueto que estava na base do conceito, pois os longos e profundos vales afastaram a maior parte dos bairros da área urbana consolidada. Os primeiros destes bairros residenciais serão o Bairro Económico dos Penedos Altos (1941 e 1949-52), na colina a norte da ribeira da Carpinteira; o Bairro do Rodrigo, de moradias geminadas (1948-51), na zona baixa junto à estação; o Bairro da Biquinha (1964), no extremo poente da cidade (Fernandes, 2009: 47) ${ }^{13}$. 
Ao contrário de outras cidades e vilas portuguesas que registaram a habitual função catalisadora da estação de comboio, sobretudo na transição dos séculos XIX-XX, a Covilhã, e certamente por razões topográficas, iria permanecer por mais algumas décadas alcandorada nas encostas da montanha, sem ter uma "baixa". Só por volta de meados do século XX o desenvolvimento da zona baixa da cidade, desenhada em torno da estação de caminho-de-ferro, começa a ganhar definição de uma nova centralidade através da introdução do tribunal (1957), da penitenciária, de escolas e de bairros residenciais de diferentes tipologias. Todavia, com um resultado deficiente em termos de espaços públicos, a justificar uma urgente intervenção paisagística com visão global para reordenar todo o conjunto (Fernandes, 2009). Na zona central, o plano "modernizador" de João Aguiar implicou a destruição do antigo largo, um espaço de crescimento orgânico, consolidado ao longo dos séculos, no qual sobressaía o edifício filipino dos Paços do Concelho (1614). Entre 1944 e 1958 altera-se radicalmente a configuração da área central da cidade num novo Centro Cívico à imagem do regime, intervenção que constitui um caso único na época de transformação radical da praça principal de uma pequena cidade. Para além do novo edifício da Câmara Municipal e do redesenho da praça, introduzem-se aí novos equipamentos representativos - Caixa Geral de Depósitos, Correios e o Teatro-Cine.

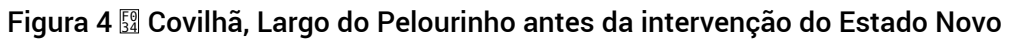

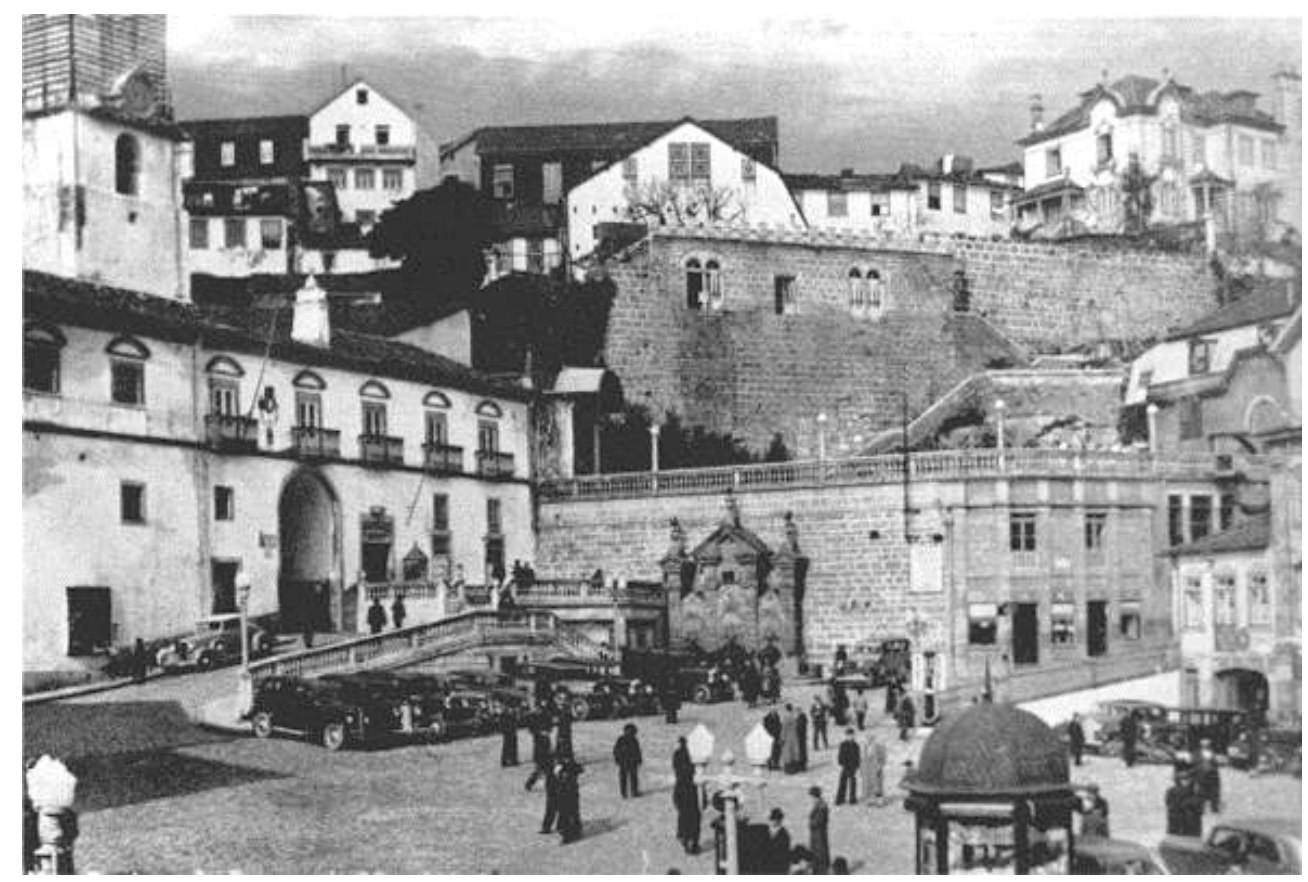

O mesmo arquitecto (Fernandes, 2009: 47-49) destaca ainda a importância simbólica e funcional de outros três equipamentos do mesmo período, que marcam a paisagem urbana pela sua imponência: o Hotel Solneve, "sinal da percepção de um novo turismo de montanha", materializado também ao estilo neoclacissizante; a Garagem de São João, de imagética inovadora (com um "mapa gigante" da Península Ibérica com a marcação das estradas e cidades principais), reflexo da generalização dos transportes rodoviários pontuando uma nova entrada na cidade; e o Mercado Municipal, equipamento comunitário emblemático encostado à antiga muralha. Importa ainda lembrar o simbólico Sanatório dos Ferroviários das Penhas da Saúde (Cottinelli Telmo, 
1945), que constituirá uma marca significativa na paisagem, e se encontra hoje em processo de conversão para Pousada ${ }^{14}$. Como sintetiza Margarida Souza Lôbo:

A transformação da imagem global da cidade da Covilhã no período do Estado Novo constitui um caso paradigmático de uma intervenção que, com os meios disponíveis, marcou de forma indelével as cidades e vilas do país. Com a reconfiguração do largo central da cidade e sua envolvente, de acordo com a linguagem identitária do regime, a sua ligação através de uma nova via com passeios amplos à Estação dos Caminhos-de-Ferro, a construção de novos equipamentos e a promoção de novos bairros de habitação social, o arquitecto João Aguiar alcança o objectivo definido por Duarte Pacheco. (2009: 38-39)

Figura 5 落 Covilhã, Garagem de São João

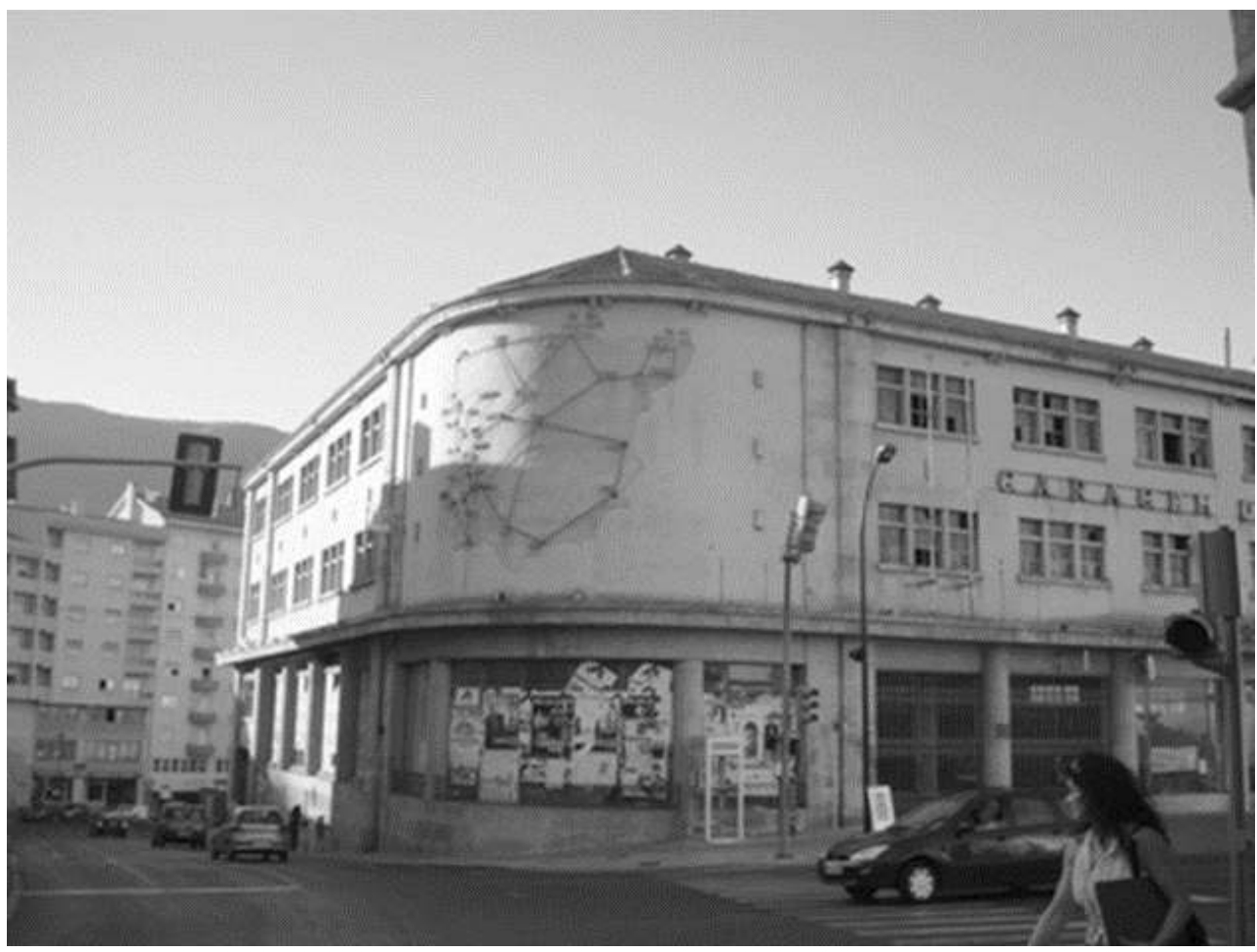

No início dos anos de 1960 a Covilhã - ainda uma cidade industrial - era uma das duas urbes mais populosas do interior do país ${ }^{15}$. O período seguinte, até à década de 70 , é fraco em termos de crescimento urbano, por oposição aos "ciclos fortes" do pombalismo em Oitocentos e do Estado Novo, tendo gerado apenas alguns edifícios pontuais dignos de nota. O Plano Geral de Urbanização, reestruturador da cidade e subúrbios, elaborado nos anos de 1970 pela Hidrotécnica Portuguesa, nunca chegou a ser aprovado. Consequentemente, o PGU de 1957 permaneceu como instrumento de ordenamento territorial até à primeira geração de PDM (Plano Director Municipal), que na Covilhã só aconteceria em 1999, sendo já impossível pensar um perímetro urbano contido. Mesmo se alguns planos de pormenor foram sendo realizados, a desadequação progressiva do PGU resultou em consequências desastrosas para o espaço urbano, excessivamente fragmentado e descontínuo, para além da deterioração dos espaços agrícolas e naturais.

Chegados à fase da «explosão» terciária, o principal investimento corresponde à introdução do ensino superior na Covilhã. A conversão do Instituto Politécnico (1973) em Instituto Universitário (1979) e, finalmente, em Universidade (1986) veio gerar 
novas sinergias na economia e na sociedade locais, atenuando os efeitos da crise profunda associada ao declínio da indústria de lanifícios. A decisão de criar uma universidade na Covilhã conduziu à opção por localizar as estruturas universitárias no seio do tecido urbano, subdivididas em pólos, reutilizando-se em grande parte as antigas instalações industriais que estavam devolutas e em ruínas ${ }^{16}$. Pretendia-se que a instalação desses diferentes pólos viesse revitalizar zonas e edifícios abandonados, rejeitando-se o modelo de campus universitário segregado da cidade central.

A função universitária estabelece-se então como a principal alavanca da economia e do desenvolvimento da urbe. Dos pontos de vista urbanístico, arquitectónico e paisagístico, as transformações associadas à Universidade da Beira Interior e sobretudo à equipa do arquitecto Costa Cabral foram significativas ${ }^{17}$. Vão-se caracterizar por linhas gerais de orientação de valorização das pré-existências e da paisagem urbana. Esta postura enquadra-se no contexto geral das obras do arquitecto, na sua busca por uma expressão moderna e urbana, atenta ao lugar, onde a paisagem assume um papel muitas vezes central ${ }^{18}$. A cidade saiu revitalizada pelo novo grande equipamento, que, em contrapartida, fez disparar a expansão urbana desregrada na zona baixa, onde se assiste à estruturação da cidade linear acompanhando o eixo Tortosendo - Covilhã Teixoso (TCT), com os hipermercados, o Centro Hospitalar da Cova da Beira, os hotéis, o parque desportivo, as zonas industriais e as novas zonas residenciais. Em 2006, concluiu-se nesta zona a construção da Faculdade de Ciências da Saúde, revelando uma atenção particular quanto à integração volumétrica no local ${ }^{19}$.

Figura 6 通 Covilhã, Pólos da UBI no tecido urbano

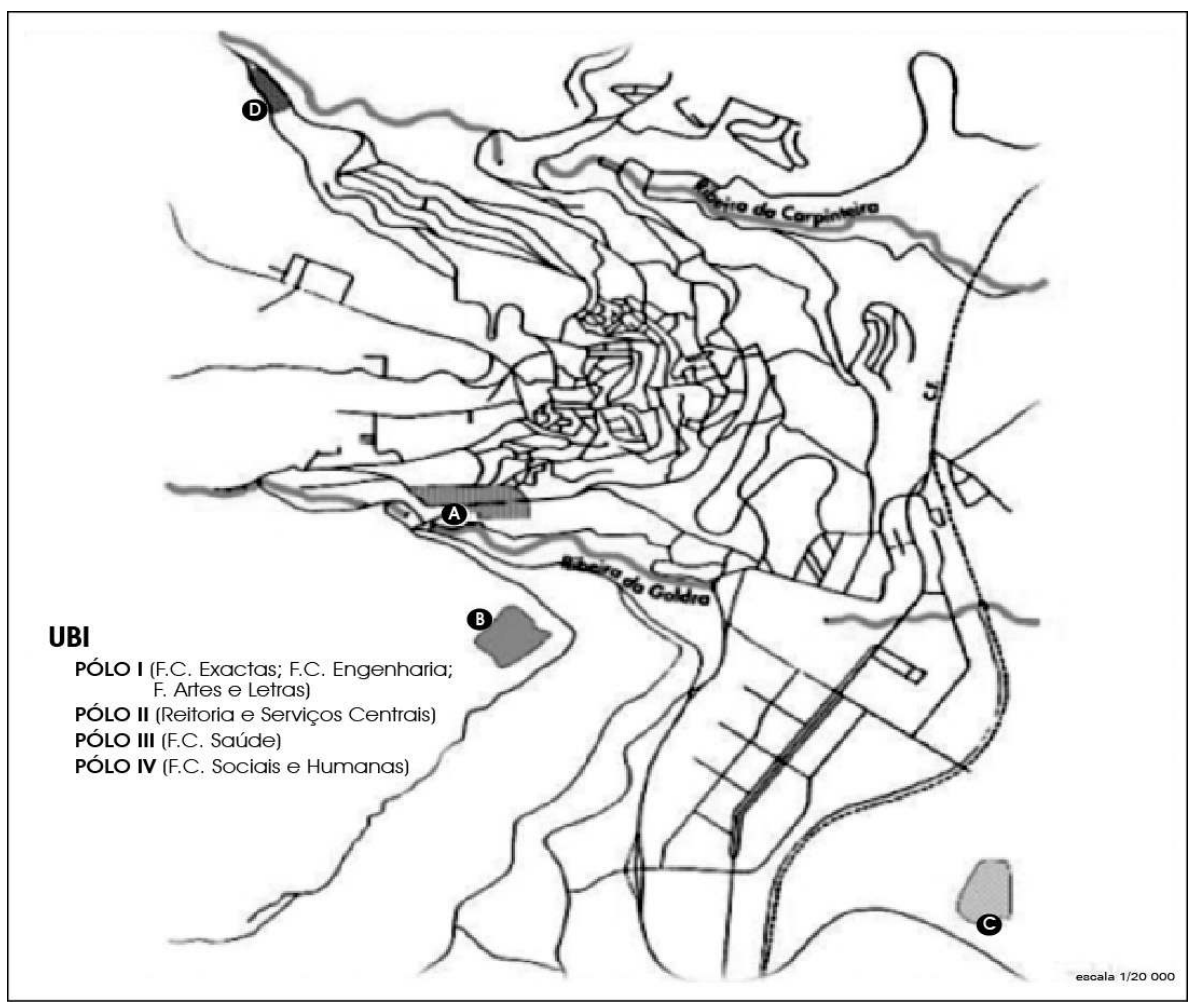

A expansão da cidade para a zona de vale desenvolve-se de uma forma desconexa da cidade antiga, sem um desenho de conjunto coerente com a topografia do território, sendo avançado como principal factor da degradação paisagística generalizada a 
inadequação dos instrumentos de planeamento que, quando existem, estão alheados das especificidades topográficas, paisagísticas e identitárias do território, levando à "ocultação das majestosas vistas panorâmicas que são (ou eram) uma das mais-valias da cidade". Já o escrevemos e partilhamos as observações alertando para a degradação acelerada da paisagem urbana covilhanense sobretudo nas últimas décadas, contaminada pela construção de edifícios de fracas qualidades arquitectónicas e urbanísticas, levando ao esvaziamento de valores históricos, culturais, ambientais e paisagísticos (Vaz, 2004, 2004a, 2010; Pereira, 2005; Matos, 2009; Fernandes, 2009; Matos, 2010; Cabral, 201020).

30 No dealbar do milénio o Programa Polis ${ }^{21}$ surgirá como uma tentativa de inverter este declínio no âmbito do urbanismo, da paisagem e do ambiente, apontando para a melhoria da qualidade de vida na Covilhã e apelando para a sensibilização e participação da população local no processo. Este programa será apresentado como uma oportunidade para reconectar a cidade com o seu território, através de um diálogo equilibrado com a montanha em termos de paisagem e ecossistema. Quase em simultâneo são aprovados o PDM (1999) e o Plano Estratégico da cidade - instrumento de apoio à implementação do PDM -, aos quais se ajusta o Programa Polis (2001: 19-20). Todavia o Plano de Ordenamento do Parque Natural da Serra da Estrela só em 2009 foi aprovado, o que revela mais uma vez o atraso das medidas de proteç̧ão do património natural.

31 Os arquitectos J. Manuel Fernandes (2009) e Ana Milheiro (2009) afirmam que, embora o Polis aponte uma nova visão reestruturante da cidade, as obras de arquitectura e paisagismo resultantes, atribuídas a diferentes equipas, algumas externas, apresentam níveis de qualidade discrepantes. As intenções do plano são assim desvirtuadas nalguns casos. Cremos que a falta de cultura urbanística, de consciência ambiental e de sentido estético dos decisores e dos projectistas foram as principais causas da fraca qualidade de algumas obras. A deficiente execução das mesmas veio piorar os resultados.

Figura 7 臨 Covilhã, Ponte “Polis” dos Penedos Altos ${ }^{22}$




Todavia, é impossível negar que o Polis-Covilhã veio desbravar caminho para um novo conceito de cidade e dotá-la de alguns espaços verdes de lazer qualificados, essenciais para a melhoria da qualidade de vida e dignificação da cidade. A Covilhã apresentava-se inegavelmente como uma candidata de peso ao programa: "Cidade de fronteira, com uma evolução demográfica favorável (...), constituindo um pólo universitário e defendendo um património arquitectónico desactivado de raiz industrial, possuía um forte potencial de influência sobre a região, aspecto igualmente determinante" (Milheiro, 2009: 56). O Polis-Covilhã parte da ideia de reconquista da paisagem. Centrase na requalificação paisagística e urbana das zonas das ribeiras, implicando as propostas do Plano de Pormenor da Carpinteira e do Plano de Pormenor da Goldra ${ }^{23}$. Propõe a introdução de jardins e parques, o enquadramento paisagístico dos edifícios existentes, a recuperação do património industrial, a articulação dos tecidos urbanos e a ligação entre as duas margens das ribeiras através de pontes pedonais. Reforçar-se-ia deste modo a importância da Covilhã no sistema urbano regional e nacional, promovendo-se paralelamente os conceitos de "cidade verde, do conhecimento e intergeracional" (Programa Polis, 2001: 9). Todavia, o urbanista que coordenou o programa lamentará dois acontecimentos que desperdiçaram oportunidades lançadas: o facto de o município não ter promovido a participação da população nos processos de decisão, e de os autores do Polis-Covilhã não terem sido consultados aquando da atribuição de alguns projectos a outras equipas, projectos esses que resultaram por vezes em soluções de fraca qualidade ${ }^{24}$. Até à actualidade, de entre os projectos previstos pelo Programa Polis-Covilhã, muitos ainda não se realizaram. Sabendo-se que a proposta assentava na promoção da mobilidade pedonal e dos valores paisagísticos, algumas obras previstas e não concretizadas contribuem grandemente para a perda do sentido global do Polis ${ }^{25}$.

Figura 8 [5] Covilhã, hipermercado Serra Shopping

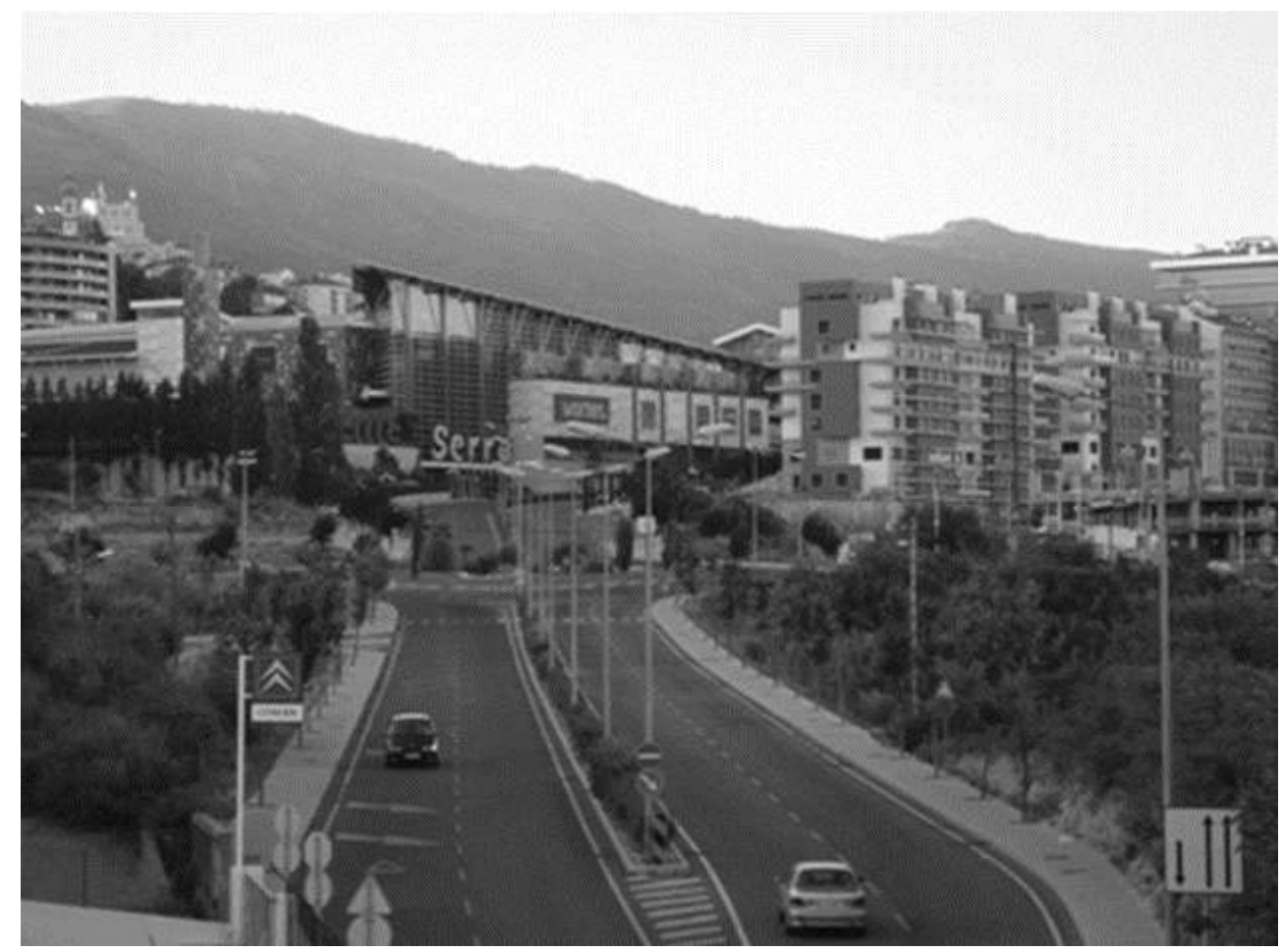

Forum Sociológico, 21 | 2011 


\section{Considerações finais} serrana, é o conjunto e a diversidade da paisagem e ambientes que singularizam a Covilhã. A beleza e carácter singular da cidade em diálogo com a montanha, que se revela não só fisicamente, mas como referente e memória, como a descrevem os autores consultados, parece hoje ter-se diluído na paisagem urbana. Considera-se, portanto, necessário discutir as razões que levaram à escassez de planificação urbana com um efeito devastador na paisagem. Para além de uma débil cultura de planeamento urbanístico, os planos de urbanização foram demasiado morosos na elaboração e pouco eficazes da acção, sugerimos razões culturais. Parece ser muito problemática a noção cultural e simbólica do valor da paisagem que poderia servir muitas vezes como travão da descaracterização da imagem do território, desencadeada pela expansão urbana pósindustrial.

Ressalvando raras situações, a montanha ou a paisagem não surgem como inspiradoras de forma urbana ou arquitectónica. Como excepções notáveis apontam-se algumas das instalações da UBI e algumas das intervenções do Programa Polis, com obras de valor desigual mas que, no conjunto, ensaiam uma nova visão reestruturante da cidade. No extremo oposto temos a expansão urbana na planície que sugere um processo que envolve "grande desperdício imobiliário», onde sobressai o edifício do Serra Shopping, que vai buscar referências ao imaginário da montanha e se sobrepõe a tudo o resto à volta. O afastamento da cidade relativamente ao espaço natural como elemento simbólico e identitário tem o seu pior corolário, levando ao desordenamento paisagístico e funcional do espaço urbano. Não obstante, a actualidade da questão da qualificação dos ambientes urbanos e da conservação do carácter tradicional dos núcleos antigos resulta da compreensão da importância destes aspectos para a sustentabilidade das cidades. Admitimos que na Covilhã a reinvenção da identificação com o território de montanha pode constituir um ponto de partida capaz de ancorar a criação de uma nova marca urbana, daí o interesse em estimular o debate técnicocientífico e cívico.

\section{BIBLIOGRAFIA}

CABRAL, B. C. (2005), A Universidade e a cidade, Covilhã, Edição da Universidade da Beira Interior.

CASTRO, F. (1990 [1947]), A Lã e a Neve, Lisboa, Guimarães Editores.

DAVEAU, S. (1969), "Structure et relief de la Serra da Estrela”, Finisterra, IV (7), pp. 31-63.

DIAS, A. P. (2006), "Bartolomeu da Costa Cabral a traço cheio", Arquitectura e Construção, 35, pp. 78-83. 
DOMINGUES, Á. (coord.) (2006), Cidade e Democracia: 30 anos de transformação urbana em Portugal, Argumentum, Porto.

FERNANDES, J. M. (2009), “Covilhã, uma leitura de síntese: estrutura urbana, conjuntos edificados e arquitecturas, sua evolução”, IHRU Monumentos. Cidades, património, reabilitação. Dossiê: Covilhãa, a cidade-fábrica, 29, pp. 40-53.

LÔBO, M. S. (2009), “Covilhã: planos de urbanização à época de Duarte Pacheco”, IHRU Monumentos. Cidades, património, reabilitação. Dossiê: Covilhã, a cidade-fábrica, 29, pp. 30-39.

MATOS, M. C. (2009), "Ponto, linha, plano: a edificação universitária na Covilhã”, IHRU Monumentos. Cidades, património, reabilitação. Dossiê: Covilhã, a cidade-fábrica, 29, pp. 110-119.

MATOS, M. J. P. (2010), Paisagens Urbanas Contemporâneas de Montanha - Para uma abordagem conceptual em Arquitectura na Covilhã, Dissertação de Doutoramento Europeu em Arquitectura, apresentada à UBI (co-parceria Université Paris 8), Covilhã.

MILHEIRO, A. V. (2009), "Por uma cidade amável. Espaços públicos e Programa Polis na Covilhã”, IHRU Monumentos. Cidades, património, reabilitação. Dossiê: Covilhã, a cidade-fábrica, 29, pp. 54-61.

MINISTÉRIO DO AMBIENTE E ORDENAMENTO DO TERRITÓRIO (2001), Viver a Covilhã. Programa Polis - Plano Estratégico, Lisboa, Edição do Programa Polis, Ministério do Ambiente e Ordenamento do Território.

NEVES, F. P. (2008), “A literatura e a reelaboração da memória das cidades”, in D. Vaz (org.), Cidade e Território: Identidades, Urbanismos e Dinâmicas Transfronteiriças, Lisboa, Celta Editores, pp. 65-72.

PEREIRA, D. (2009), “A estrutura urbanística da Covilhã entre a Idade Média e a Idade Moderna”, IHRU Monumentos. Cidades, património, reabilitação. Dossiê: Covilhã, a cidade-fábrica, 29, pp. 16-23.

PEREIRA, T. (2005), “Uma ideia para a cidade da Covilhã - Candidatura ao Prémio Sir Robert Matthew. Prize Nominee UIA", Lisboa, Ordem dos Arquitectos.

PINHEIRO, E. (1997), “O património industrial covilhanense: uma memória a preservar e a musealizar”, Separata de Arqueologia Industrial, I (1-2), 3. érie, pp. 89-110.

PINHEIRO, E. (2009), “A Universidade da Beira Interior e o seu papel na reabilitação e reutilização do património industrial da Covilhã”, IHRU Monumentos. Cidades, património, reabilitação. Dossiê: Covilhã, a cidade-fábrica, 29, pp. 98-109.

PROENÇA, R. (ed.) (1985), Guia De Portugal, tomo II, Beira Baixa e Beira Alta, 2.. ed., Lisboa, Fundação Calouste Gulbenkian, pp. 723-735 e pp. 891-895.

QUINTELA, A. M. (1990 [1899]), Subsídios para a Monographia da Covilhan, Covilhã, Tip. d'«O Rebate».

RAMOS, M. S. (2003), Café Montalto, Lisboa, D. Quixote.

RIBEIRO, O. (1994), Opúsculos Geográficos, V Volume: temas urbanos, Lisboa, Fundação Calouste Gulbenkian.

RODRIGUES, J. M. (2009), “Covilhã: evolução urbana da cidade”, IHRU Monumentos. Cidades, património, reabilitação. Dossiê: Covilhã, a cidade-fábrica, 29, pp. 6-15.

SANTOS, J. M. (1997), Escritores do Concelho da Covilhãa: Notas Biobibliográficas, Covilhã, Edição de autor.

SILVA, J. A. (1996), História da Covilhã, Covilhã, Edição de autor. 
TORGA, M. (1980), Portugal, 4. a ed., Coimbra, Gráfica de Coimbra.

VAZ, D. (2004a), “As cidades do interior e as estratégias ausentes: uma observação a partir da cidade da Covilhã”, Cidades: Comunidades e Territórios, 8, pp. 21-33.

VAZ, D. (2004b), Cidades Médias e Desenvolvimento: 0 caso da cidade da Covilhã, Covilhã, Edição da Universidade da Beira Interior.

VAZ, D. (2010), "Patrimonio urbano serrano: urbanismo tradicional y cultura obrera en Covilhã", Ciudades, 13, pp. 201-218.

\section{NOTAS}

1. Atendendo ao caldo social e de cultura operária produzido na cidade, particularmente a partir do século XIX e até aos anos 80 do século XX. A expressão "cidade-fábrica" tem sido utilizada para caracterizar a Covilhã desde, pelo menos, Manuel Nunes Geraldes (cf. Geraldes, M. N., 1880, A Covilhã no Centenário, Lisboa, Lallement Frères; Pinheiro).

2. Nuno Teotónio Pereira citado por Maria João Matos (2010: 253).

3. Nuno Teotónio Pereira citado por Ana Vaz Milheiro (2009: 57).

4. De referir que a «Metrópole da Lã», ou a «Manchester Portuguesa», como era designada a Covilhã, possuía, antes da crise de 1960, cerca de 140 fábricas de lanifícios e seis mil operários que produziam 66\% do fabrico total dos lanifícios portugueses (Guia de Portugal, F. C. G., 1985: 725).

5. A expedição científica composta por 36 especialistas foi "guiada" por um pastor sabugueirense. Veja-se Suzanne Daveau (1969), "Structure et relief de la Serra da Estrela", Finisterra, vol. IV, n.ำ 7, pp. 31-63.

6. Respectivamente Eduardo Malta (1900-1967) e Alberto Roseta (1915-1990).

7. Raul Costa Camelo citado por José Aires da Silva (1996: 155).

8. Para o relato deste processo, ver Arthur de Moura Quintela (1899: 25-26), citando Padre Pina.

9. Gil Vicente - "Frágua de Amor", Obras de Gil Vicente (J. Victorino Barreto Feio, J. C. Monteiro), Hamburgo, edição de Laughoff, 1834, tomo 2, p. 442. (in J. M. Rodrigues, 2009: 10,15).

10. Juntamente com as fábricas no Fundão e em Portalegre.

11. “(...) A mesma Fabrica (...) para se pôr em prática necessitava de se applicarem à obra d'ella a pedraria dos muros arruinados d'essa Villa (...)." Carta Régia de 12 de Maio de 1769; citada por José Miguel Rodrigues (2009: 15).

12. No contexto do ciclo de planeamento desencadeado por Duarte Pacheco, no que diz respeito à cidade da Covilhã, destaca-se a figura do arquitecto João António de Aguiar, responsável, simultaneamente, pela concepção do Largo do Pelourinho, pela elaboração do projecto do novo edifício da Câmara Municipal (1947), pelo Anteplano Geral de Urbanização da Covilhã (terminado em 1951 e com homologação ministerial de 1947) e pelo Plano Parcial de Urbanização da Área Compreendida entre o Largo do Pelourinho e a Estação de Caminho de Ferro (1960).

13. Para uma apresentação dos bairros ver: Hélder de Oliveira, 2005, Descrição dos Bairros, texto policopiado.

14. Nas Penhas da Saúde o esqui será praticado desde apenas 1932, data em que João dos Santos Simões e António Lopes fundaram o Ski Clube de Portugal. Em 1936 funcionou nas Penhas da Saúde a primeira escola de esqui. Era dirigida pelo prof. Slavicsek, austríaco do Tirol (Guia de Portugal, 1985: 734).

15. A Covilhã, com 23000 habitantes em 1960, era a mais populosa aglomeração urbana do interior do país ao norte do Tejo (incluindo Viseu), da mesma grandeza que Évora (25 000) (Orlando Ribeiro, 1994: 261). 
16. Foram recuperadas velhas instalações fabris junto à ribeira da Goldra (Pólo I) e à ribeira da Carpinteira (Pólo IV), o Convento de St.o António (Pólo II), e o Pólo III desenvolve-se com a Faculdade de Ciências da Saúde já no início do século XXI numa área nova de expansão da cidade.

17. Ana Paula Dias (2006), Elisa Pinheiro (2009), Madalena Cunha Matos (2009) e Maria João Matos (2010).

18. Ao arquitecto Bartolomeu Costa Cabral é reconhecido um talento especial na concepção de instalações para o ensino superior, tais como o Pavilhão do Instituto Superior de Agronomia, Lisboa, 1991; a Faculdade de Engenharia da Universidade Católica Portuguesa, Sintra, 1996-2001; a Universidade do Minho, 1986 e 1998, onde também aplica os princípios que veremos nas suas realizações para a UBI, ou na reconversão de edifícios com valor patrimonial: o projecto em Lisboa da recuperação do Teatro Taborda, Colina do Castelo (1981).

19. Desenhada pelo arquitecto José Carlos Loureiro.

20. Bartolomeu Costa Cabral citado em Maria João Matos (2010: 268).

21. Liderado pelo arquitecto Teotónio Pereira, com a colaboração do arquitecto paisagista Luís Cabral, o Polis-Covilhã consubstancia uma política urbana baseada num conjunto de acções de requalificação urbanística e ambiental dos vales das duas ribeiras, polarizadoras da indústria de lanifícios, rearticulando-os com o centro urbano (2001).

22. Desenhada pelo arquitecto Carrilho da Graça (2009).

23. Os dois Planos de Pormenor foram dirigidos pelos arquitectos Teotónio Pereira e Luís Cabral, igualmente responsáveis pelo Programa Polis.

24. Nuno Teotónio Pereira citado por Maria João Matos (2010).

25. Entre as obras por construir encontram-se quatro das cinco pontes previstas sobre as ribeiras, um dos dez acessos verticais mecânicos, o Museu da Cidade e o Centro de Monitorização/Interpretação Ambiental programados para a antiga Fábrica António Estrela e os dois jardins previstos para a ribeira da Carpinteira, onde se planeava a criação de "jardins temáticos botânicos de montanha" (Programa Polis, 2001: 44).

\section{RESUMOS}

É reconhecida à Covilhã uma desqualificação formal e paisagística, firmada em paralelo com o afastamento da cidade do espaço natural e de montanha que havia moldado a sua função e feição geo-histórica. Considera-se, portanto, a necessidade de reflectir o sentido global da estruturação urbana, tendo em vista permitir uma leitura para o ordenamento qualificador desta urbe multissecular e interrogar as razões que levaram a que um tal capital simbólico não tenha sido objecto ou apenas tido uma débil apropriação nas opções locais de planeamento urbano.

It is acknowledged that Covilhã has a formal and landscape disqualification, caused by the removal of the city from its mountain and natural space, that had shaped its features and geohistorical nature in the past. Therefore, it is essential to reflect upon the overall sense of the city's urban structure while intending to provide a text for the urban planning of this multisecular center and investigate the reasons why this symbolic capital has not been considered, or at most mildly considered, facing the local options of urban planning. 
ÍNDICE

Palavras-chave: lanifícios, montanha, paisagem, universidade

Keywords: wool manufacture, mountain, landscape, university

\section{AUTOR}

\section{DOMINGOS VAZ}

Departamento de Sociologia da Universidade da Beira Interior e CesNova, Centro de Estudos de Sociologia da Universidade Nova de Lisboa,dmvaz@sapo.pt 